\title{
La localización urbana de las políticas culturales: bases para un análisis sociológico en la comunidad autónoma del País Vasco ${ }^{1}$
}

Jesús Arpal Poblador

Iñaki Domínguez Vázquez

Universidad del País Vasco. Departamento de Sociología II

\section{Resumen}

El artículo plantea cómo la cultura, como demanda característica de la sociedad moderna, precisa de políticas culturales, asimilables al concepto de política social, sobre las que descansa la reproducción de la sociedad y la producción de orden social.

Palabras clave: políticas culturales, sociología urbana, País Vasco, espacio urbano.

Abstract. The urban location of the cultural policies: basis for a sociology analysis in the Basque Country.

The article deals with culture as main demand of modern societies. These societies need to develop cultural policies, conteptually similar to social policies, in order to further society reproduction and social order.

Key words: cultural policies, urban sociology, Basque Country, urban space.

\section{Sumario}

1. Políticas socioculturales

2. Servicios, representación social y localización urbana

3. Cuestiones metodológicas
4. Rasgos de las políticas socioculturales del País Vasco

Bibliografía

\section{Políticas socioculturales}

Desde mediados de los sesenta se viene insistiendo en las profundas reestructuraciones de la sociedad industrial/urbana (tecnologización y terciarización, flexibilización y alteración de las clases sociales, desurbanización, carácter masivo

1. Este trabajo se enmarca dentro de otro más amplio realizado con una ayuda de la Universidad del País Vasco, en el que, junto a los autores, han participado Gotzone Mora, Ma Angeles Oiarzabal e Iñaki Unzueta. Asimismo, ha constituido parte del marco teórico de sendos estudios realizados para los ayuntamientos de Vitoria-Gasteiz y San Sebastián. 
de la democracia, generalización del consumo, mundialización, etc.) y, de forma especial, sobre la redefinición de la cultura, correlativamente a estas transformaciones. La vieja dicotomía cultura/civilización se replantea en términos de cultura cultivada frente a cultura de masas (o con la detección de una forma creciente de cultura - mid cult - coincidente con el reconocimiento de una nueva representación de la sociedad: el hombre medio u hombre de la calle, la opinión pública y el gusto actual o popular). (Bell, MacDonald, Shils, 1974).

En cualquier caso, la confrontación entre la racionalidad de «los que saben» y la "del público" sólo pueden resolverse en esta sociedad como "participación» (Dumont, 1979: 14). Los fenómenos de industrialización, mercantilización o consumismo se relacionan con el desarrollo del carácter "pop" de la comunicación por imágenes o la importancia de la reproducción. Esta explosión de lo cultural afecta al propio término cultura, que es objeto de múltiples definiciones, y al espectro de las actividades culturales, cuyo registro está sufriendo una continua ampliación.

El modelo que conocemos como democratización de la cultura no es sino la concreción en el campo cultural de un modelo de crecimiento que afecta al conjunto de las sociedades capitalistas a partir de 1945 y que, en el caso que nos ocupa, nacía con el objetivo de intervenir sobre las situaciones de desigualdad social generadas en el ámbito de la cultura. El planteamiento de las políticas de democratización de la cultura parte del reconocimiento de esta desigualdad en el acceso a la cultura, debida, como señala Depaigne, a "condiciones de tipo tanto económico y social como geográfico. Por tanto, uno de los afanes de la política cultural habrá de consistir en eliminar semejantes desigualdades" (1980: 76).

En este sentido, el concepto de política cultural resulta asimilable a la noción de "política social», que puede definirse como una «intervención en la realidad, mediante acciones que asignan recursos escasos para lograr aumentar el bienestar de la población en su conjunto, lo que en general se logra disminuyendo los sectores que viven en siruación de pobreza ${ }^{2}$. Así, a las ramas de actuación más frecuentes de una política social ${ }^{3}$, determinados Estados - y, particularmente, el francés a partir de la creación en 1959 del Ministerio de Cultura-, añaden la cultura.

2. Esta definición se debe a R. Franco (1984: 331). No obstante, otros planteamientos, como el de $\mathrm{P}$. de Laubier, añaden a esta noción un matiz más marcadamente político, al señalar la forzosa progresividad de este tipo de acciones políticas: "por política social se entenderá aquí el conjunto de medidas tomadas al nivel de una nación con objeto de mejorar, o de cambiar, las condiciones de vida material y cultural de la mayoría de acuerdo con una toma de conciencia progresiva de derechos sociales y teniendo en cuenta las posibilidades económicas y políticas de un país en un momento dadon (D. Casado, 1985).

3. Entre los sectores más tradicionales de la intervención pública se encuentran la sanidad (que pretende establecer una garantía de asistencia), la educación (garantía de enseñanza), el trabajo (garantía de empleo), la vivienda (garantía de acceso a la vivienda), los seguros sociales (garantía de obtención de rentas), los servicios sociales (atención a grupos vulnerables: ancianos, toxicómanos, etc.). 
Por otra parte, si la cultura - y el acceso generalizado a ella - puede aparecer como una demanda característica de la sociedad moderna, del bienestar y del ocio, o postindustrial (por la terciarización y la necesidad de reinventar los códigos de interpretación o de resolver masivamente los universos simbólicos), son las políticas culturales, los servicios y equipamientos culturales, uno de los campos preferentes sobre los que descansa la reproducción de la sociedad y la producción de orden social. La necesidad de «tiempo libre» (tiempo separado del de la producción industrial), ya sea como aspiración social o como exigencia sobrevenida por la incapacidad de pleno empleo en las sociedades industriales, ha replanteado la función social de las actividades culturales (y su consideración política y económica). Como expresión de los problemas de reproducción ordenada de la sociedad, de integración de los grupos y los individuos, se producirá una renovada atención a los servicios sociales, cuya función no será sólo asistencial, sino de contribuir al desarrollo de sistemas de integración social y personal. Problemas que se generarán y se expandirán específicamente en las ciudades, en el modo de vida urbano que define a la sociedad industrial. Las ciudades han venido siendo sistemas de inclusión y exclusión de las poblaciones y del conocimiento; de los actores y de la cultura. En tanto la ciudad en su propia organización física del espacio y del tiempo es una representación acabada de la vida colectiva, y en tanto las cotrelaciones entre estructura social y estructura espacial - tal como se van resolviendo en las grandes ciudades - son representativas de un orden dinámico y estable, los equipamientos y servicios ofertados y desarrollados en la ciudad serán la auténtica representación de la sociedad del bienestar (aspiración de la sociedad industrial y que ha orientado a las poblaciones, y los estilos de vida y los sistemas de valores, en términos generales y concretos). El desarrollo social precisa de un sistema de solidaridades; pero para que éstas puedan ejercitarse y aplicarse hay que intervenir en las matrices de la construcción de la integración o agregación social que son las «localidades urbanas».

La preocupación europea por el tema de un desarrollo social integrador y solidario en la crítica situación económica mundial, se centra en resolver la desintegración o insolidaridad que se produce paradigmáticamente en las ciudades (Conferencia de Lille, mayo de 1991). La preocupación no descansa, sin embargo, en la discriminación o exclusión económica. El problema es que se trata de "una exclusión social y cultural que se inscribe en el espacio y en territorios determinados, muy particularmente en el corazón de las metrópolis urbanas europeas" (Jacquier, 1991: 8). En definitiva, podría plantearse que:

a) Las grandes cuestiones sociales ( $y$ las políticas tendentes a su atención) se presentan en las sociedades avanzadas como cuestiones y políticas culturales por lo que tienen de problemas de integración social o de socialización.

b) Los problemas del "tiempo libre» tienden a afrontarse como ocio activo (al menos en colectivos clave para la reproducción social o en segmentos de la vida cotidiana que afectan a la integración personal) y ello remite a la actividad cultural. 
c) La dominancia de lo urbano y su concreción en ciudades lleva a la necesidad de previsiones e intervenciones locales (interurbanas e intraurbanas), dando especial significación a lo que las ciudades suponen de matrices de cultura.

d) El urbanismo como ciencia y técnica de la ordenación de ciudades recurre a la determinación de centros (su localización y definición funcional) como sistema de ordenar la ciudad y de orientar las redes urbanas.

e) Las personas y los grupos demandan localizaciones estructuradas (centros de un sistema) del espacio social para orientar sus acciones (para obtener una representación de la práctica social).

Desde una óptica inversa no es extraño el predicamento de las políticas culturales como políticas de regeneración urbana, reactivación económica o integración social (Bianchini, 1990). En este sentido, resulta programática la declaración de Bremen (mayo de 1983). Además del énfasis en la importancia social y económica del desarrollo cultural (que se entiende como abierto al cambio, pluralista y descentralizado), se subraya la conveniencia de que la práctica política y ciudadana se localice a efectos de que se genere la participación activa de los grupos (especialmente los jóvenes y las minorías étnicas). Todo ello plantea una redefinición de la presencia de las instituciones políticas, que empieza a cuestionarse en el Estado español, y de lo que representan las actividades culturales.

Este fenómeno, el de la descentralización, es, al mismo tiempo, un reflejo de una actitud generalizada en el conjunto de las administraciones públicas de los países europeos occidentales, relacionada con la exigencia de una mayor eficacia en la gestión, como un requisito ineludible derivado de las características propias de lo cultural, de las condiciones en que tienen lugar la creación, la producción, la difusión y el consumo de los bienes y servicios culturales. En este sentido, conviene señalar la incongruencia de una política cultural que pretenda un acercamiento de la cultura a los individuos o una mejora en su capacidad de acceso a los bienes y servicios culturales, como hacen los postulados de los paradigmas de política cultural conocidos, si la intervención pública no refleja esta misma cercanía y, sobre todo, no acepta el supuesto de que la creación es privativa de los individuos y grupos de la sociedad civil.

En cualquier caso, al margen de estos aspectos, existe otro fenómeno derivado de la aplicación más actual de las políticas culturales que consideramos de singular importancia: nos referimos a la cada vez más frecuente interrelación de la intervención pública en la cultura con otras actuaciones políticas, vínculo que se manifiesta en toda su extensión en el ámbito local, en la actuación de los ayuntamientos. De esta ligazón se derivan aspectos y cuestiones que las diferentes instituciones, incluso las del mismo ámbito de lo local, abordan desde su particular perspectiva, mostrando una enorme pluralidad de soluciones en las que se perciben los rasgos propios de sus respectivas estructuras sociales, esto es, el producto de las relaciones sociales presentes en cada sociedad. Pero también, como consecuencia de esta aplicación de las políticas cul- 
turales en el ámbito local, se produce una paulatina dispersión de los límites de lo cultural y de las actividades así calificadas, en un proceso en el que las actividades culturales municipales abarcan tanto facetas cercanas a la regeneración industrial o urbana como a las acciones de integración social de grupos marginados.

Todos estos procesos configuran un objeto de estudio caracterizado por una tremenda dispersión, con multitud de planteamientos y agentes interactuando y, en ocasiones, complementándose, cuando no solapándose. De todo ello, se desprende una multiplicación de las formas de entender qué es cultura, que afectan al entendimiento común de cómo debe ser la intervención pública y qué funciones debe satisfacer. Cada Administración y casi cada institución, hacen referencia a un concepto propio de cultura, que se concreta en una enorme variedad de planteamientos y fórmulas de aplicación que hacen mucho más costoso, aunque también más complejo y rico, el análisis de las políticas culturales. Veámoslo más detalladamente.

\section{Servicios, representación social y localización urbana}

En una sociedad con dificultades para integrar (producir agregación social y orden institucional/organizacional) a través de las estructuras y organizaciones de producción primaria y secundaria (crisis más notable en el sector industrial puesto que se identificaba en ella tanto la base del mercado y la riqueza -y el acceso al consumo y al desarrollo- como el patrón y estilo de vida más representativo - el ritmo de vida y el trabajo industrial-), los servicios plantean un sector de amplia significación productiva y simbólica; realizan la propuesta de «los equipamientos del poder» (Estado providencia), pero no sólo como desarrollo del control y la integración en el Estado (reclutamiento); sino también como identificación de bienestar no sólo económico y social: el consumo (y la producción) de servicios ocupa crecientemente a la población, genera renta, genera agregaciones sociales (corporativas, vecinales, de edad o sexo), socialización y orden social. De la relación directa (individual y colectiva) con los servicios no queda excluido ningún segmento de la población ni ningún nivel de la vida social.

Por otra parte, el concepto de servicios es el más globalizador, puesto que excede del terciario, y se plantea como servicios a todas las actividades, de ahí que la red de servicios permita articular y representar (como una totalidad ciudadana) como algo reconocible y ordenado, la diversidad y fragmentariedad o separación de la actividad colectiva (VV.AA., 1994: 9-12). Los servicios plantean la "inexcusable participación de los clientes", lo que provoca "localizaciones preferentemente urbanas" (Moreno, Escolano, 1992: 84), afectando a la estructuración del espacio urbano (diferenciación funcional y áreas sociales).

Las estrategias de intervención en la estructura espacial y especialmente en las correlaciones estructura social/estructura espacial (las delimitaciones y localizaciones como organización de la representación global), plantean "casos" objeto de análisis crítico en la renovación urbana: Las renovaciones de la pobla- 
Cuadro 1. Indicadores de participación y representación

\section{La política sociocultural como}

Representación, entendida como:

- mediación;

- organizaciones formales (políticas, económicas, laborales);

- equipos y programas (gubernamentales y no, públicos y privados).

\section{Objetivos}
a) legitimación de las instituciones $y$ los organismos
b) integración de los colectivos y los ciudadanos en las instituciones
c) orientación de las demandas de base
d) explicitación e interrelación de los organismos y los grupos
e) objetivación de las políticas
f) formación de expertos.

Participación, entendida como:

- activación de grupos y dinamización social (actores básicos);

- movimientos sociales;

- formación ciudadana (creación de valores, conocimientos y redes).
a) socialización (formación para la participación)
b) intervención y actuación (control y desarrollo de actividades
c) reconocimiento de movimientos sociales (protagonismo de la sociedad civil)
d) crítica «de base"
e) formación cívica (en solidaridades sociales y en identidad cultural)
f) dotación de contenidos al ocio y a lo no ocupacional
g) formación y activación del voluntariado.

ción ( $y$ de su estructura demográfica, de actividades y venta) pueden reorientar o corregir los fenómenos de marginados o no integrales); también se plantean ejemplarmente en todas aquellas políticas que descansan en los distintos censales: la generación de rentas fiscales o la distribución del voto, así como la seguridad ciudadana o la organización del tráfico; la funcionalidad de la administración o la eficacia de los servicios y de los equipamientos plantean cuestiones de modulación socioespacial (tamaño y estructura ideal de las unidades o áreas socioespaciales), que se plantean tanto desde la revisión de los límites espaciales como desde la modificación estructural de la población. Las intervenciones en la morfología urbanística (cambios en la calificación y en la acomodación del suelo, cambios en la vialidad y en el tráfico para plantear nuevas o redefinidas interrelaciones, cambios en los equipamientos) suponen cambios en la estructura social (supuesta una determinada correlación).

El problema se plantea ante la dificultad de resolver y controlar las realimentaciones entre distintos niveles o segmentos de la morfología funcional y ante las incertidumbres sobre el comportamiento de los actores sociales ante esta movilización o alteraciones de la estructura urbanística (especialmente si se tiene en cuenta su autonomía relativa por referencia a su ubicación dentro 
de un sistema social (de clases sociales, de ciudades, de mercado, de Estado, etc.) no siempre válido para analizar la práctica. Los centros como "puntos» de la red (como en un sistema de acupuntor) llevan a una sistematización abstracta o a una indeterminación ante la práctica real que resolverán los actores.

\section{Cuestiones metodológicas}

Las políticas culturales, en sus objetivos, diseño y aplicación, se plantean cada vez más y de manera explícita como políticas sociales por referencia al estado de bienestar y a sus crisis. Incluso en sus aspectos de organización práctica y en su desarrollo estrictamente técnicos, esta conciencia es clara: las actividades son "acciones que girando en torno a lo sociocultural como concepto "bisagra" - entre campos artísticos, creativos, educativos y de identidad cultural relacionados con la expresión individual o social- contribuyen a la consecución del objetivo último de la intervención social, que es conseguir una mejora de la calidad y de las condiciones de vida de los individuos» (Miralles, 1992: 25).

Desde esta perspectiva, y para el análisis propuesto en esta investigación, podrían resumirse los siguientes puntos:

a) Dimensión cultural de las políticas sociales: Todo lo que las políticas y los programas sociales tienen de construcción de representaciones mentales o mundo simbólico (valores, creencias, concimientos), especialmente en lo que significan como ideas generalizables sobre la vida social y sus problemas (formación de opinión, conciencia, ideología, etc.).

b) Dimensión social de las políticas culturales: Todo lo que las políticas y los programas de actividad cultural tienen de funciones de integración social, de creación de mentalidades acordes con los problemas sociales y el bienestar, de identificación de los sectores y los grupos sociales problemáticos (orientación y formación de los valores, creencias, conocimientos que acompañan a una política social, tanto en las agencias titulares como en los usuarios y demandantes o el público en general).

c) Dimensión local de las políticas sociales y culturales: Las distintas escalas de espacio social en las que se generan y se aplican estas políticas y fundamentalmente en lo que tienen de diferentes ámbitos de poder - administrativo y de representación o participación de los ciudadanos (desde la CAPV a lo municipal y sus distintas desagregaciones; desde la organización burocrática y técnica, más o menos centralizada y unificada, a los espacios de autoorganización o atención "espontánea» de los problemas sociales).

\subsection{Los servicios culturales}

El recurso a lo sociocultural (sistema de representación de alta codificación simbólica) y a sus centros, actividades, actores y programas o políticas, se justifica metodológicamente: 
- Las representaciones de lo colectivo (de la agregación) socialmente producidas, apuntan más a las conductas y a los sistemas de valores, a las orientaciones y al sentido de las acciones cuando se tiene en cuenta el sistema simbólico (sistema de legitimación = político cultural).

- Las actitudes, relaciones, acceso o consumo de cultura como formalmente (organizacional o institucionalmente) producidas caracterizan a las sociedades del bienestar (como bienes más sofisticados o servicios superiores).

- El poder estatal (y otros ámbitos de lo público y de lo privado) no sólo se legitima en la producción y en el consumo de cultura, en el logro de la accesibilidad y de la variedad y creatividad de la oferta, sino que genera rentas y empleo especialmente flexibles.

- La centralidad metropolitana se relanza, especialmente en cuanto a centro del poder y de la participación democrática de masas, a través de la activación de lugares y sedes de cultura que activan la ciudad (y la estructuran) y el sistema de ciudades.

- La indefinición o flexibilidad de los productos culturales (dentro de su carácter de respuestas a cuestiones existenciales) plantea formas amplias de participación y representación (autoorganización, autogestión, desarrollo de públicos - especializados y masivos-).

- Dentro de la concepción de los servicios como «equipamientos del poder» o agencias de integración social, los servicios de cultura tienen la máxima representación colectiva según varios niveles o ámbitos:

a) Su disponibilidad y flexibilidad para la intervención de los poderes públicos que plantean con frecuencia lo cultural como el escenario más apropiado para la producción de imagen, tanto de los organismos como de la ciudad en su conjunto.

b) La capacidad de la actividad cultural para integrar organizaciones no gubernamentales, grupos informales e iniciativas de los ciudadanos al mismo tiempo que potencian --por su dimensión simbólica- la identidad colectiva.

c) La proyección y accesibilidad de los servicios de cultura que, en principio, se dirigen a todos los ciudadanos y que son percibidos como los equipamientos más representativos de las sociedades postindustriales.

d) La posibilidad de desarrollos en redes y de localizaciones en centros culturales que, al mismo tiempo que plantean desarrollos abiertos y flexibles, establecen puntos de conexión concretos en el espacio urbano; lo cual les hacen susceptibles de funcionar como agencias de planificación urbanística.

\subsection{Representación social y participación colectiva}

El concepto de representación social ha de tomarse - en este caso- en un sentido específico, tal como tiende a definirse en recientes orientaciones de la sociología y la psicología social, fundamentalmente a partir de las propuestas 
de Moscovici (Jodelet, 1989): se trata de una forma de conocimiento, de un dotar de sentido a nuestras acciones, a las experiencias, que no se analizan en cuanto acto mental — sistema cognitivo-, sino en lo que tienen de conocimiento socialmente producido; es decir: en las propias interacciones y relaciones con otros humanos o con la naturaleza; en la propia experiencia de interdependencia, se producen unas construcciones de sentido que, por una parte, dotan de significado y valor a los objetos y a los hechos -lo cual orienta nuestro comportamiento- $y$, por otra, dan sentido a la propia experiencia de interdependencia: básicamente hacen inteligible lo social y la sociedad como la forma necesaria de vida humana; secundariamente, dan el mapa en el que ubicar las distintas acciones experimentadas. En ambas perspectivas, el sentido que se produce -la simbolización y la interpretación-- es compartido y generalizable; viene a ser el «sentido común». En definitiva, la representación social implica tanto las construcciones mentales como las interacciones y relaciones desde las que éstas se producen; y en la tradición durkheimiana, poniendo el énfasis en su dimensión de agregados y de colectivos estructurados. Así pues, la ciencia social de las representaciones se ocupa preferentemente de estos mapas mentales generalizados y de estas prácticas que tienden a producir y reproducir esas "clasificaciones" básicas o ampliamente compartidas. En ella, lo material y lo mental; los objetos y los sujetos se ponen en relación indisociable y constituyen un continuo proceso de socialización y aculturación. En su desarrollo analítico ha de tenerse en cuenta que la representación puede objetivarse «en los discursos», «en las palabras», «en los mensajes» y «en las imágenes mediáticas"; pero también "en las conductas y en las actuaciones materiales y espaciales" (Jodelet, 1989: 32). En la sencilla exposición subsiguiente, nos atendremos, sobre todo, a dos derivas de esta propuesta metodológica:

a) Las normas - más o menos formalizadas - como representación de las personas, los grupos y sus actos (en nivel institucional).

b) Los lugares - concreciones espaciotemporales-- como representativos de la práctica social (en nivel de los movimientos sociales y de la vida cotidiana).

Lógicamente este concepto de representación se contrapone, en cierto nivel teórico, con el de presencia: la representación tiene algo de intermediación, de no percepción directa, de falta de presencialidad o ausencia (Lefebvre, 1980). Y, desde esta perspectiva, se pueden relativizar la representación y la participación, tanto cuando se hacen a través de discursos y de personas interpuestas, como cuando se hacen a través de lugares que median en nuestras relaciones. En nuestro caso, puede servir para una crítica de la representación estrictamente política (crítica de las ideologías y los intermediarios), en contraste con una representación directamente social; $y$, en ambos casos, remite al tema de la participación. Participación que puede ir de la mera "consulta» por parte de las autoridades a la "acción colectiva organizada»; y que adquiere características especialmente significativas en el ámbito de las actividades que exceden de la pura producción industrial: en el «campo del ocio» (Samson, 1986). 
Los problemas de las sociedades industrializadas y urbanizadas, especialmente la conciencia de limitación de recursos y la importancia concedida al control privado del propio bienestar, han "estimulado la emergencia de la participación en todas sus formas [...]. El pluralismo de los valores, el ascenso de movimientos sociales como el ecologisrno, una utilización más intensa del territorio y la elevación del nivel de instrucción y cultura, es decir de consciencia [...] han acentuado la necesidad del público (habría que decir de los públicos) de estar presente en los asuntos, de ocuparse de sus asuntos. En contrapartida, las asociaciones y las instituciones de todo orden han decidido, o han sido obligadas a tomar en consideración el ambiente social, económico y físico en sus procesos de toma de decisión" (Thibault, 1986: 11).

Este replanteamiento no sólo afecta a los políticos y al pueblo, a los programadores y gestores y a los receptores de servicios, sino que afecta también a las propias ciencias sociales que tienen que refinar sus instrumentos de consulta (los distintos métodos de encuesta o de observación); desde este punto de vista, la investigación-acción en los lugares en que se produce la representación y la participación tendría un especial interés. Finalmente, y dentro de esta breve exposición metodológica, nos fijamos en centros ćvico-culturales por su variada e integral significatividad.

a) La ambigüedad de su denominación plantea precisamente que se trata de lugares en los que el ejercicio de la cultura se entiende con un ejercicio ciudadano; bien sea porque en la cultura se representa la civilidad, es decir, la vida colectiva; en cualquier caso son centros de vida social con especial atención a la actividad cultural.

b) Se trata de espacios físicos construidos y activados por personas y grupos que los conciben y los practican como lugar de encuentro entre las políticas institucionales y los movimientos sociales; entre los programas y las actuaciones. Son escenarios en los cuales se representan las dos caras de la sociedad: el orden institucional y los actores (una oferta y una demanda de servicios); de ahí el interés que tiene la específica forma de resolver esa interrelación: sistemas de dirección y participación en los distintos niveles (diseño, gestión y aplicación de los programas y locales).

c) Estos lugares, al centrar la vida cívica y cultural (las personas y las ideas), dan un sentido ordenador de la experiencia, organizan la vida colectiva en el espacio urbano. En tanto "la sociedad industrial es urbana» y el urbanismo pretende solucionar teóricas y prácticas con validez universal (Choay, 1965: 7-9), estos centros cívico-culturales, desarrollándose en las ciudades, tenderán a estructurar las redes que activan la vida urbana; serán referencias y lugares de encuentro que darán sentido a la dinamicidad del urbanita; contribuirán, en su propia resolución urbanística, a dar sentido y organización a las alternancias entre trabajo y ocio, entre público y privado que caracterizan a la moderna sociedad industrial.

d) Por otra parte, en lo que la cultura tiene de universo simbólico, de organización de signos y significados para afrontar la experiencia, estos centros 
funcionan como depósitos de códigos y mensajes, como espacios de comunicación en los cuales puede pretenderse la representación y participación en la construcción de lo social; es decir, como lugares de socialización y aculturación. Más allá de la familia y la escuela, los centros culturales - precisamente por su carácter cívico- pueden funcionar como agencias específicas de construcción de la personalidad, como espacios de la representación de sí mismo y del otro, lo cual plantea una "sociología del sujeto» y especialmente "el análisis de la formación y transmisión de modelos de representación de sí mismo" que han de entenderse en "la articulación entre el sistema cultural y el sistema social", en «las grandes fracturas de la estructura social que, al especificar las posiciones de los grupos, les dotan de un punto de vista propio sobre sí mismos y sobre su entorno". (Kellerhals, Lalive d'Epinay, 1987: 5-6).

\subsection{La dimensión local urbana}

La aplicación de los diferentes modelos de intervención pública en la cultura que han caracterizado la acción de la mayoría de los Estados europeos en las últimas décadas, no encuentra fácil acomodo en el ámbito local, debido fundamentalmente a las singularidades del espacio urbano que lo diferencian de ese otro espacio más amplio y difuso que es el Estado, al que la propia ciudad sirve en ocasiones como instrumento mediador.

En la sociedad postindustrial la ciudad se muestra a sí misma fragmentándose, haciendo de concretas intervenciones urbanísticas el propio objeto de la exhibición. Las metrópolis compiten y se reproducen en el propio espectáculo de su renovación y, lo que es más significativo, esta renovación no se produce tanto como respuesta a necesidades de racionalización de la vida colectiva (como los planes generales), ni siquiera responden a una ampliación del escenario para una mejor actuación del poder. Las construcciones espectaculares en las que se resume y se concentra la representación de las ciudades modernas tienen su razón en sí mismas, en su espectacularidad.

Curiosamente, en el ámbito de lo local confluyen tanto esta tendencia a la espectacularización del propio espacio urbano con la simultánea espectacularización de las iniciativas del poder político, sobre todo en aquellos aspectos en los que la intervención de los poderes públicos roza lo simbólico y se introduce en lo artístico y lo cultural. En este sentido, la aplicación de las políticas culturales en las ciudades tiene un especial significado, tanto porque paulatinamente han ido complementando y casi sustituyendo a la iniciativa de la Administración central, como porque la intervención de las administraciones locales tiene características singulares en su relación con el espacio y la construcción de las representaciones sociales de la población. Pero, sobre todo, las políticas culturales locales adquieren su especial relevancia por cuanto son el instrumento de una intervención global, en la que lo más sobresaliente, aquello que reclama más atenciones, es lo cultural, lo que pretende convertirse en símbolo y representación de la propia ciudad. 
Estas líneas de actuación de lo público — que no son únicas sino enormemente plurales, con una gran variedad de soluciones en las que se perciben rasgos propios y se aprecia el influjo de las relaciones sociales presentes en cada sociedad-, muestran una creciente separación entre, por un lado, las acciones de carácter sociocultural y aquellas otras de índole espectacular, cercanas al concepto de representación social antes seńalado. Preciso es recordar, en este sentido, que las representaciones se materializan, en primer lugar, en las personas y los grupos (su modelo típico sería la representación política); pero son, asimismo, vehículos de representación social los lugares físicos que, al reconocerlos o usarlos, permiten objetivar los complejos niveles de interacción y de organización a través de los cuales los "mapas mentales" orientan el comportamiento de los individuos y los grupos.

De tal forma que resulta una triple articulación entre estructuras (y especialmente redes y puntos de interacción), instituciones y organizaciones (con las personas y los grupos representativos de las mismas) y localizaciones (particularmente lugares de articulación de esas estructuras y esas instituciones con los distintos actores sociales). Por consiguiente, la localización en la trama urbana de los centros de actividad y las propias distancias y relaciones entre centos suponen la experiencia física desde la que se construyen los mapas mentales que orientan la actividad de los ciudadanos (tanto dirigentes como dirigidos).

En este sentido, son los lugares de decisión de las políticas culturales, fundamentalmente las instituciones locales (patronatos, ayuntamientos, diputaciones, cajas de ahorros, etc.), los que articulan un primer nivel de ese mapa y esa red, y son los centros de actividad (casas de cultura, bibliotecas, museos, locales de espectáculos, salas de exposiciones, auditorios, etc.) los que organizan el mapa físico-mental y los flujos a través de los cuales se definen las redes de interacción y se orientan las acciones de los ciudadanos. En cualquier caso, se trata del encuentro de la representación formal o mediada con la representación activa e inmediata. Esta representatividad de la ciudad puede analizarse en tres niveles:

a) La ciudad como específica práctica y representación de lo social: estructuración dinámica de los grupos y las actividades, intercambio de los recursos; que se concreta analíticamente en áreas diferenciales e interrelacionadas y en movilidad (con los distintos niveles de objetivación que la práctica conlleva).

b) Los centros institucionales como lugares de actividades y relaciones sociales, expresivos de una división del trabajo - a nivel elemental y complejo- que, en su propia localización y en sus locales, expresan esa división y representan aspectos estructurales de la sociedad, especialmente como agentes de producción y reproducción de un orden.

c) Los ciudadanos como actores o activadores de la ciudad (vida urbana), lo cual se produce según cierta topología teórico-práctica: la ciudad como espacio social representativo y actuable y los lugares urbanos como centros estructuradores de esa representación práctica. 
Estas perspectivas entendidas como procesos: como ciudadanos produciéndose en ciudad en centros urbanamente producidos; o como ciudades producidas desde la actividad de ciudadanos en centros urbanos. Todo ello desde la dimensión organizativa y normativa — de integración y orden social- que suponen los procesos de institucionalización.

$\mathrm{Y}$, dejando por un momento este rasgo de la ciudad como espacio de representación, debemos señalar que de entre las diversas tendencias de la intervención de los poderes públicos locales, no siempre es la más común la que busca la alteración del espacio urbano como modo de intervención en la realidad social. Bien al contrario, son numerosos los municipios que plantean su oferta en el ámbito de lo cultural mediante un abanico de actividades culturales que se despliega desde facetas cercanas a la regeneración urbana hasta las acciones de integración social de grupos marginados.

Evidentemente, esta emergencia de lo cultural en la acción política de las administraciones públicas locales se produce como resultado o en relación con otras estrategias centradas en lo social, lo económico o lo político. Es una aplicación básicamente instrumental: la cultura entendida como instrumento en la diversificación, reconstrucción, mantenimiento, consolidación o desarrollo de las ciudades, incluyendo a las industrias culturales locales dentro del amplio abanico de la producción industrial, aunque no necesariamente con una dedicación o unas prerrogativas especiales.

Nuevamente, nos encontramos con una interpretación de lo cultural que, si bien no está centrada sobre lo "simbólico espacial», como ocurre con la intervención basada en la edificación monumental y espectacular, sí actúa en un nivel de la vida colectiva en el que lo cultural está restringido a la interpretación que de él hace el Poder. Es preciso, por tanto, llegar hasta un tercer tipo de políticas culturales para alcanzar a observar los límites de la participación ciudadana en la creación de la propia ciudad. Este tercer tipo es el constituido en torno a los denominados centros civicos o centros socioculturales. En ellos coinciden tanto la participación ciudadana, sin la que difícilmente tendrían sentido, como la necesidad de un espacio físico: el equipamiento urbano. Los centros cívicos son, por tanto, el instrumento idóneo para la intervención pública: permiten la actuación sobre el espacio urbano y su alteración; posibilitan una labor regeneradora de espacios físicos o sociales en declive; $y$, por fin, legitiman la acción política mediante la cesión de un espacio para la participación ciudadana.

Dicho con otras palabras, los centros cívicos reúnen, al menos sobre el papel, los rasgos centrales a los que venimos haciendo referencia: la representación social y la participación colectiva. Pero, también, como consecuencia de la aplicación de las políticas culturales en el ámbito local, se produce una paulatina dispersión de los límites de lo cultural y de las actividades así calificadas, en un proceso en el que las actividades culturales municipales abarcan tanto facetas cercanas a la regeneración industrial o urbana como las acciones de integración social de grupos marginados.

Todos estos procesos configuran un objeto de estudio caracterizado por una tremenda dispersión, con multitud de planteamientos y agentes interactuando 
y, en ocasiones, complementándose, cuando no solapándose. De todo ello, se desprende una multiplicación de las formas de entender qué es cultura que afectan al entendimiento común de cónno debe ser la intervención pública y qué funciones debe satisfacer. Cada Administración y casi cada institución hacen referencia a un concepto propio de cultura, que se concreta en su enorme variedad de planteamientos y fórmulas de aplicación que hacen mucho más costoso, aunque también más complejo y rico, el análisis de las políticas culturales.

La dimensión local de la actividad cultural (y de cualquier otro orden) está provocando una renovada atención de los agentes sociales, en gran parte por la nueva escala de los fenómenos humanos. La mundialización cuestiona y replantea, en las empresas y en las instituciones públicas, en el mercado y en la política, el lugar correspondiente a las actividades y a las interacciones de todo tipo, y muy particularmente en aquellos ámbitos que afectan a lo simbólico (la construcción de identidad) y a la dinamización y a la integración de los actores sociales (la representación y la participación de los ciudadanos).

De manera correlacionable, las cuestiones en torno a la descentralización (especialmente de las decisiones y de los servicios) redefinen tanto la organización funcional (y muy especialmente la ordenación del territorio base de la provisión de equipamentos) como la administración y la representación de los ciudadanos. La atención a las políticas y a los programas de desarrollo local se ha reactivado; en la propia crisis económica, la vitalidad de las ciudades intermedias en Italia (y las redefiniciones del sistema de ciudades y de la centralidad metropolitana) o el interés de las políticas y de la intervención en lo cultural y local como instrumento de regeneración urbana (con experiencias modelo en Europa) han vuelto a plantear los problemas de escala, tanto por una eficacia en la actividad como para una participación de los actores sociales.

Pero dentro de las propias ciudades se vuelven a plantear problemas de morfología y estructura (la articulación de la ciudad en distintos barrios, áreas funcionales o cualquier otro sistema de zonación), al mismo tiempo que cuestiones de organización de la representación y presencia de los ciudadanos (no sólo en la representación política formalizada en los ayuntamientos, sino también a través de organizaciones y asociaciones cívicas); fundamentalmente desde dos perspectivas: el replanteamiento de la estructura económica (el tópico de la terciarización reformulado duramente con la crisis industrial) y las nuevas jerarquías y desarrollos de las ciudades (ante el hundimento del modelo de ciudad industrial). Ambos ejes atañen fundamentalmente a lo cultural; bien como sector terciario (servicios) de la estructura global, bien como ciudad desindustrializada (o reorientada a los servicios para la industria), el campo de la actividad cultural cobra una renovada significación.

Si a ello añadimos los problemas de integración de colectivos en progresiva diferenciación (categorías de edad, deficiencias e incapacitaciones físicas y psíquicas, pobreza, paro), la cultura en cuanto a universo simbólico para la consolidación de identidades, y también en cuanto a campo susceptible de actividades flexibles y que descansan sobre todo en el "capital humano", puede generar ocupación no sólo laboral, sino también del ocio. 


\section{Rasgos de las políticas socioculturales del País Vasco}

En el País Vasco actual, atendiendo a las tendencias observables tras el proceso de cambio político desarrollado fundamentalmente en los años ochenta, las prácticas culturales se producen según un cuadro de situación, cuyas líneas fundamentales podrían esquematizarse de la siguiente manera:

a) Se suele partir de una cultura diferencial, con fuerte identificación en la lengua, que se reproduce de forma relativamente cambiante dentro de un universo cultural o sistema de valores, de límites imprecisos y en transformación: la industrialización y la urbanización (y sus crisis), los nuevos sistemas de comunicación, la mundialización y la universalización de la cultura, se confrontan con una cultura particular identificada como propia, autóctona y distinta, lo cual provoca tensiones que se definen, en primera instancia, como políticas, pero que también plantean desarrollos específicamente culturales (en los medios de comunicación y en la creación).

b) El cambio social, fundamentalmente como industrialización y urbanización, se realimenta con el cambio político (básicamente el paso del franquismo a la democracia y el desarrollo de las instituciones autonómicas); esto produce desplazamientos en los agentes sociales y en las organizaciones productores de cultura; los centros se alteran y las demandas se redefinen.

La propia Iglesia católica como institución que propone modelos culturales, que incide en la práctica cultural (y que tiene cambiantes funciones sociales y de servicios, además de significación política diversa) experimentará profundas transformaciones. El desarrollo de la Administración autónoma (la CAV) planteará transferencias de las competencias del Estado desde el final de los sesenta, particularmente en el ámbito cultural, además de dar un nuevo marco a la cultura autóctona. El desarrollo de la administración vasca planteará problemas sobre el nivel de descentralización externa e interna. La Ley del Territorio Histórico supondrá una importante transferencia de competencias económicas y especialmente en materia de cultura a las diputaciones.

c) En otro sentido, los particulares procedimientos por los cuales distintos grupos en el País Vasco afrontan la resistencia al franquismo o su final superación, suponen ciertos desarrollos de la diferencia cultural con tendencias a la representación social y política. Al mismo tiempo, esta situación marca modelos de desarrollo de la cultura al margen de las instituciones político-administrativas; el desarrollo de la Administración autónoma incidirá en esos modelos. En este proceso, la representación y la participación en centros institucionales tendrá diversos signos, según partidos políticos o movimientos sociales.

d) La crisis económica, y especialmente la de sectores de producción significativamente localizados en el País Vasco planteará no sólo limitaciones relativas en los recursos; se originarán crisis en los patrones de representación 
colectiva, redefinición de los centros urbanos y una relevancia de los comportamientos desviados y de la marginación social que excitará el desarrollo de políticas socioculturales y movimientos sociales críticos que se expresarán culturalmente.

La situación desde la que se produce el desarrollo cultural del País se puede concretar, si consideramos su estructura de lugares y actores:

- Fuera de algunos proyectos de representación institucional política (orquesta nacional), del desarrollo de la Red de Radio y Televisión (EITB), dependiente de la Consejería de Cultura del Gobierno, o los derivados de la política lingüística o de las transferencias en educación y servicios sociales, gran parte de la política cultural y de los equipamientos serán competencia de las diputaciones con variaciones significativas según territorio, partidos dominantes y gestores $\mathrm{o}$ activadores de las demandas.

- En las tres provincias (Guipúzcoa, Vizcaya y Álava) se dan distintas propuestas, a partir de un mínimo de programas y equipamiento (locales básicos, escuelas de actividades elementales, programas de divulgación y extensión) concentrarán en sus capitales una parte de la actividad cultural: precisamente la que representa centralidad o jerarquía urbana de servicios, producción avanzada (tecnológica o creativa), con proyectos y desarrollos relativamente diferenciados.

La capitalidad administrativa de la CAV en Vitoria no afecta directamente al desarrollo cultural dada la autonomía del Ayuntamiento y su peso poblacional en la provincia de Álava. La crisis de los grandes sectores industriales que afectan directamente a Bilbao y su entorno, más los intentos de implantar en las otras provincias elementos de la administración y de la infraestructura que pueden afectar a su centralidad y jerarquía metropolitana, excitarán una reordenación urbana y proyectos de terciarización y especialmente de centros de cultura. La especialización turística de San Sebastián renovará moderadamente su urbanismo y desarrollará algunos centros y programas de actividad ampliando su anterior estructura. Será el Ayuntamiento de Vitoria el que, a partir de un urbanismo consolidado, propondrá una política social y cultural -fuertemente implicadas - según un modelo de integración máxima de los ciudadanos y unas políticas básicamente sociales, todo ello descansando en el Ayuntamiento. Sin embargo, su política de equipamiento urbano para la cultura y las actividades sociales, no sigue el modelo de grandes promociones especializadas y activadoras que plantea Bilbao y, en menor grado, San Sebastián (y que han provocado polémicas sobre sus objetivos, representatividad y participación). En un rápido esbozo, plantearemos un análisis de estos tres casos y su representatividad.

En el País Vasco, además del debate que provocó en su día las transferencias en materia cultural del Gobierno del Estado a la CA y del gobierno de ésta a las diputaciones, el propio planteamiento de las DOT (Directrices de Ordenación Territorial) ha reexcitado la polémica sobre la jerarquía funcional 
de las ciudades de la Comunidad (sistema polinuclear de capitales), y muy particularmente en cuestiones de capitalidad cultural. Al mismo tiempo, los planteamientos para la salida de la crisis, especialmente en las densificaciones urbanas (Guipúzcoa 2.000, Bilbao Metrópoli 30), y los propios planes generales o parciales de la intervención urbanística local remiten a proyectos culturales de manera significativa.

Desde este punto de vista y cińéndonos a las instituciones públicas en cada una de las localizaciones específicas (Bilbao, San Sebastián y Vitoria), las políticas culturales que se producen en las capitales de los territorios tienen, entre otros, los siguientes rasgos:

a) En el caso de Bilbao, y de forma un tanto esquemática, podemos decir que los equipamientos culturales (en este caso denominados centros cívicos) desarrollan buena parte de la oferta institucional cultural de su Ayuntamiento. Es decir, no toda la oferta "producida" en los centros cívicos puede ser atribuida a la labor del Ayuntamiento de Bilbao y, además, de entre toda esta oferta que, como tendremos ocasión de apreciar, es variada y plural, hay numerosas actividades que difícilmente podemos aceptar sin más como «actividades culturales».

El Área de Cultura y Turismo del Ayuntamiento de Bilbao realiza anualmente un buen número de actividades culturales que oscilan entre la función y la creación de infraestructuras hasta llegar a las actividades de carácter general y ámbito universal basadas en lo espectacular. De una manera general, las actividades del Área de Cultura y Turismo resultan bastante significativas del concepto de "cultura" manejado, al que de una manera prudente podríamos calificar de ecléctico, capaz de albergar tanto actividades de promoción cultural en las escuelas como espectáculos para todos los públicos y fiestas populares, pasando, como queda dicho, por actividades de conservación y mantenimiento del patrimonio cultural municipal.

Otro aspecto llamativo es la universalidad de la oferta que, excepción hecha de las actividades para escolares - como la animación musical o la enseñanza de danzas vascas en las escuelas-, no están dirigidas a un público específico. Por último, aunque parezca sorprendente, la ausencia en la relación precedente de actividades basadas en la explotación de los teatros Arriaga o Ayala, o el Festival Internacional de Cine Documental, no se debe a ningún olvido. Son entidades autónomas sobre las que el Área de Cultura y Turismo no tiene control alguno, a pesar de que el Ayuntamiento es el único accionista de la empresa que gestiona el Teatro Arriaga o el volumen de subvenciones que recibe el Festival Internacional de Cine Documental.

De todo ello se desprende una doble consecuencia: por un lado, el Área de Cultura y Turismo funciona de una manera relativamente marginal a los grandes acontecimientos y proyectos culturales de la Villa. Dicho con otras palabras, sus funciones, contenidos y cometidos se centran en aquello que podríamos denominar como cultura cotidiana, organizada en torno 
a la conservación del patrimonio municipal, el mantenimiento de las instituciones culturales locales y la organización de espectáculos festivos.

Por el contrario, de esta misma dedicación se desprende que la decisión y la gestión de los acontecimientos y proyectos culturales de envergadura permanencen alejados de esta instancia burocrática (Área de Cultura y Turismo) y residen en los órganos de decisión política del Ayuntamiento. Asimismo, y sobre todo desde la renovación del carácter metropolitano de Bilbao, adquieren una importante significación los programas de la Diputación Foral (biblioteca, museos, Herriz Herri, Bizkaiko Artea, etc.), y la propia intervención del Gobierno Vasco (proyecto Guggenheim), localizados en la ciudad.

b) En el marco, todavía incierto, que potencien las DOT u otros instrumentos sectoriales del Gobierno de la CA (planes de diferente alcance en materia de bibliotecas, museos o teatro, por ejemplo; creación de entidades centrales como orquesta, ballet, teatro de la CA y determinación de sus sedes permanentes o no), San Sebastián se perfila como una ciudad intermedia, reactivando su tradición de servicios de ámbito supralocal (el turismo reorientado en parte a una cualificación de congresos y de ocio cultural) y que plantea una centralidad relativa. Dentro del sistema de ciudades en el que se inserta ( $y$ con nuevas cuestiones según se plantea el relanzamiento metropolitano de Bilbao, la activación del eje Atlántico o las conexiones con Navarra) ha desarrollado distintas definiciones: una definición de capitalidad cultural en el ámbito de la Comunidad Autónoma e incluso con proyecciones exteriores (sobre todo en una línea de cultura espectacular o de cultura del ocio); una definición administrativa de capital de provincia (del territorio histórico de Guipúzcoa) que genera centralización de flujos especialmente en los servicios; y una caracterización de ciudad central de un área metropolitana (identificada tradicionalmente en el corredor San Sebastián-Irún, pero que se proyecta al interior desde una concepción ya no de conurbación, sino de comarca urbana) planteada en los modelos urbanísticos y no suficientemente instrumentada; en parte, por su última definición: municipio con una estructura y morfología particulares: de crecimiento poblacional moderado (e incluso estancado en tiempo reciente), sin crecimiento espacial de sus límites administrativos (la anexión de entidades colindantes ha tenido un proceso tímido y oscilante a lo largo de este siglo) y que plantea una morfología interna, que más allá de sus condicionantes geográficos o de la zonación administrativa, sólo muy recientemente empieza a desarrollar una diferenciación funcional en el espacio de acuerdo con modelos típicos de zonación centro-perifería (lo cual no quita los diferentes sistemas de identificación de barrios que pueden ir desde los establecimientos dentro de la trama urbana a los de un entorno de urbanización relativa o que desbordan los límites municipales).

En términos de políticas y gestión pública y centrándonos en lo cultural, este marco se activa fundamentalmente desde dos instituciones: Diputación Foral y Ayuntamiento. Diferentes organismos públicos o para- 
públicos locales inciden no sólo en el marco, sino también directamente en la política y en la dinámica cultural de San Sebastián: los de carácter empresarial (Cámara de Comercio y sociedades públicas para el fomento o explotación de actividades específicas), junto a los de carácter social (organizaciones asistenciales o religiosas). Las cajas de ahorro merecen, sin embargo, una mención, especialmente porque desde la fusión de la Provincial y Municipal, y aunque esté en replanteamiento su política de patronazgo, se trata de un organismo de fuerte significación en la dinámica cultural (financiación, equipamiento y desarrollo de programas propios con centros propios) y en el que se pone en relación el Ayuntamiento y la Diputación (no sólo por la presencia de consejeros, sino también porque ha asumido actividades y redes del doble origen municipal y provincial).

c) En Vitoria-Gazteiz la aparición de instituciones de gestión y desarrollo de políticas de carácter sociocultural se produce con anterioridad a las primeras elecciones democráticas, en un proceso inusual en el conjunto del Estado y que, según todas las fuentes consultadas, tiene su origen en la conservación por el territorio alavés de su carácter foral tras la guerra civil.

Como detalle de esta preocupación en aspectos sociales, se citan algunos precedentes de las instituciones actuales, como, por ejemplo, la creación de las oficinas municipales de barrio y la constitución de los consejos rectores de barrio ya en 1976. De esta etapa (1976-1979) son servicios municipales como guarderías, hogares infantiles, servicios sustitutorios de la familia y servicios sociales en distintas zonas de la ciudad con funciones de animación sociocultural y con un marcado interés por el desarrollo comunitario antes que por la realización de labores asistenciales.

Con la crisis económica de mediados de los setenta, surgen las primeras iniciativas institucionales de carácter asistencial, como por ejemplo la ayuda a los parados. Posteriormente, y apoyándose en la existencia de una amplia red de infraestructuras de titularidad pública (Ayuntamiento) o semipública (cajas de ahorros), desde el Ayuntamiento se intenta paliar los efectos del «desencanto» de principios de la década de los ochenta, impulsando la creación de espacios de encuentro: los centros cívicos, que se insertan en las políticas de bienestar social, como un instrumento de prestación de servicios sociales y comunitarios, al tiempo que de información y lugar de encuentro.

En cualquier caso, las actividades de los centros cívicos no constituyen la única oferta que en el ámbito sociocultural ofrece a sus ciudadanos el Ayuntamiento de Vitoria-Gazteiz. Antes bien, la oferta municipal parece corresponder a un generoso planteamiento en el que se encuentra una fácil correspondencia entre lo cultural y lo social, cercano a determinados planteamientos teóricos sobre la labor de las instituciones públicas que, en el terreno de las políticas culturales, tiene su referente teórico más evidente en los paradigmas de la democracia cultural y, concretamente, en la consideración de las acciones culturales y las acciones sobre la cultura como instumento de regeneración social y reactivación económica. 
La función de Vitoria-Gazteiz como capital de la Comunidad Autónoma se presenta, básicamente, como una localización de la gestión políticoadministrativa (en Lauka), y no parece generar una dinámica de centralidad cultural potenciadora de la ciudad. Por su parte, la Diputación Foral de Álava se orienta, sobre todo, a políticas específicas para la provincia.

En resumen, en el País Vasco, la experiencia de la Comunidad Autónoma, no sólo plantea una estrategia de localización y descentralización del Estado, sino que también conlleva una estructuración interna de competencias y ámbitos, que ha tenido una de sus manifestaciones más singulares en las transferencias del Gobierno Autónomo a las diputaciones forales, y que plantea nuevos problemas en la delimitación de las competencias municipales, especialmente en materia de cultura.

\section{Bibliografia}

ALONSO TORRENS, FJ. (1989). «Pobreza, marginación y Estado de Bienestar en España». En MuÑoz Del Bustillo, R. (comp.). Crisis y futuro del Estado de Bienestar. Madrid: Alianza Universal.

ANDER EGG, E. (1987). «Política cultural a nivel municipal». Buenos Aires: Humanitas. ARIÑO, G. (1982). Descentralización y Planificación. Madrid: Instituto de Estudios de Administración Local.

BELTRÁN, M. (1987). «Perceptores de ingresos y familias: sobre las desigualdad en la distribución de la renta en Españam. En VV.AA.: Politica y sociedad. Homenaje a F. Murillo Ferrol. Madrid: CIS.

BELL, D. y otros (1974). «Industria cultural y cultura de masas». Caracas: Monte Ávila.

BIANCHINI, F. (1989). Urban renaissance? The arts and the urban regeneration process in 1980s Britain. Centre of Urban Studies. University of Liverpool.

BIANCHINI, F. (1990). Cultural policy and urban development. The experience of West European cities. Centre of Urban Studies. University of Liverpool.

BOSCH, A.; ESCRIBANO, C.; SÁNCHEZ, I. (1989). Evolución de la desigualdad y la pobreza en España. Madrid: INE.

CA'ZORZI, A. (1987). Administration et financement publics de la culture dans les Communautés Européenes. Bruxelless: CEE.

CASADO, D. (1985). «Apunte sobre orientaciones básicas de la actual política social». Iglesia viva, núm. 119. Madrid.

CASTELLS (1985). "Estado, cultura y sociedad. Las nuevas tendencias históricas". Ponencia del encuentro Cultura y sociedad. La politica de promoción sociocultural a debate. Madrid: Ministerio de Cultura, Ejemplar multicopiado.

COMEDIA (1991). Out of hours. Summary report. Londres.

CONSEJO DE EUROPA (1983). Ciudad y cultura. Declaración de Bremen. Consejo de Cooperación Cultural del Consejo de Europa. Documento facilitado por el M. de Cultura. Ejemplar fotocopiado.

CONSEJO DE EUROPA (1988). France. Rapport national du Programme experimental d'evaluation des politiques culturelles. Estrasburgo: Conseil de la Cooperation Culturelle.

CHOAY, F. (1965). L'urbanisme. Utopies et réalités. París: Senil.

ChOMBART DE LAUWE, P. (1991). Transformations Sociales et Dynamique Culturelle. París: Gallimard. 
DelCoURT, X.; MATTElaRT, A. y M. (1984). La cultura contra la democracia. Barcelona: Mitre.

Depaigne, J. (ed.) (1980). Politicas culturales en Europa. Madrid: Ministerio de Cultura.

DÍAZ, E. (1989). "El nuevo Contrato Social: Instituciones políticas y Movimientos sociales». En MUÑOZ DEL Bustillo, R. (ed.). Crisis y futuro del estado de Bienestar. Madrid: Alianza.

DUMAZEIDER, J. (1988). Révolution culterelle de temps libre 1968-1988. París: Meridiens Klincksiek.

DUMONT, F. (1969). «L'idée du developpement culturel: esquisse d'un psychanalyse». Sociologie et sociéte, n. XI, p. 4.

Garcfa FERrando, M. (1987). "Ocio, consumo y desigualdad social». En VV.AA.: Política y sociedad. Homenaje a F Murillo Ferrol. Madrid: CIS.

Gournay, B. (1989). "Le jugement des experts européens". Commentaire, n. 48.

HaRvey, E.R. (1990). Politicas culturales en Iberoamérica y en el mundo. Madrid: TecnosQuinto Centenario.

JACQUIER, C. (ed.) (1991). Le développernent social urbain. (Europa Sociale). (DG. V. Emploie). Lille.

JODELET, D. (ed.) (1989). Les réprésentations sociales. París: PUF.

JoR, F. (1979). La desmitificación de la cultura. Madrid: Ministerio de Cultura.

Kellerhals, J.; Lalive D'EPINAY, C. (1987). "La répresentation de soi». Etudes de Sociologie et d'Ethnologie. Ginebra: Universidad de Ginebra.

LAMBERT, M. (1987). Contenido y consecuencias de la descentralización sobre el territorio y las relaciones de poder en Francia. Madrid: Siglo XXI.

LEAL, J.; RÍOS, J. (1980). La Presence et l'absence. Contribution à la théorie des représentations. Casterman. Tournai.

MENGER, P.M. (1990). Transformation de la politique culturelle publique. Commentaire, n. 49. París.

Ministerio De CulTURA (1979). Acción cultural de los organismos internacionales europeos. Madrid.

MrNisterio De CulTuRa (1987). El mecenazgo cultural. Análisis y propuestas de acción. Madrid: Ministerio de Cultura.

Ministerio DE Cultura (1991). Demanda y equipamientos culturales de los españoles. Madrid.

MORENO, A.; Escolano, J. (1992). Los servicios y el territorio. Madrid: Síntesis.

Murillo, F; BELTRÁN, M. (1983). "Estructura social y desigualdad en España». En FOESSA: IV Informe sociológico sobre el cambio social en España. Madrid: Euramérica.

PARKINSON, M.; BIANCHINI, F. (1990). Cultural policy and urban regeneration in Liverpool: A tale of missed opportunities. Centre of Urban Studies. University of Liverpool.

Rodríguez CABRERo, G. (1989). "La política social en España: realidades y tendencias». En R. MUÑoz DEL BUSTILLO (comp.): Crisis y futuro del estado de bienestar. Madrid: Alianza Universidad.

Rodríguez SomonTe, R.; Sierra Ludwig, V. (1982). "Políticas y cuentas culturales: referencias internacionales». En Análisis e Investigaciones Culturales n. 15. Madrid.

SAMSON, M. (1986). "Introduction». Loisir \& Societè/Leisure and Society. Preses Univ. Québec, n. 9, 1, p. 7.

SÁNCHEZ CARRIÓN, J.J. (1987). "Los equipamientos culturales de los españoles». En Análisis e Investigaciones Culturales n. 30. Madrid.

SimpSON, J.A. (ed.) (1979). Hacia una democracia cultural. Madrid: Ministerio de Cultura. 
Thibault, A. (1986). "La consulation du public, au delà du symbole». Loisir \& Societè/Leisure and Society, n. 9, p. 11.

TIMms, D. (1976). El mosaico urbano. Hacia una teoría de la diferenciación social. Madrid: IEAL.

TITMUS, R.M. (1981). Politica social. Barcelona: Ariel.

UNESCO (1979). Métodos y objetivos de la planificación cultural. Madrid: Ministerio de Cultura.

URFALINO, Ph. (1989). «Les politiques culturelles: mécénant caché et académies invisibles». En L'Anne Sociologique, n. 39.

VV.AA. (1989). "La politique culturelle de la France». Commentaire, n. 48, 49 y 50. París.

VV.AA. (1989). Procesos socioculturales y participación. Madrid: Popular.

V.AA. (1994). La ciutat i la induistria. Barcelona: Institut d'Estudis Metropolitans de Barcelona.

VIDAL-BENEYTO, J. (1981a). «Hacia una fundamentación teórica de la política cultural». Revista Española de Investigaciones Sociológicas, n. 16. Madrid.

Vidal-Beneyto, J. (1981b). "Politiques culturelles et democracie". Le Monde Diplomatique, número de abril. París.

Willians, F. (1992). Social Policy. Office Cambridge. 